\title{
Detailed Film Cooling Measurements over a Gas Turbine Blade Using a Transient Liquid Crystal Image Technique
}

\author{
Hui Du, ${ }^{1}$ Srinath V. Ekkad, ${ }^{2}$ Je-Chin Han, ${ }^{3}$ and C. Pang Lee ${ }^{4}$ \\ ${ }^{l}$ Schlumberger SPT Center, Rosharon, Texas, USA; ${ }^{2}$ Mechanical Engineering Department, Louisiana \\ State University, Baton Rouge, Louisiana, USA; ${ }^{3}$ Marcus C. Easterling Chair, Department of Mechanical \\ Engineering, Texas A\&M University, College Station, Texas, USA ${ }^{4}$ GE Aircraft Engines, Cincinnati, \\ Ohio, USA
}

Detailed heat transfer coefficient and film effectiveness distributions over a gas turbine blade with film cooling are obtained using a transient liquid crystal image technique. The test blade has three rows of film holes on the leading edge and two rows each on the pressure and suction surfaces. A transient liquid crystal technique maps the entire blade midspan region, and helps provide detailed measurements, particularly near the film hole. Tests were performed on a five-blade linear cascade in a low-speed wind tunnel. The mainstream Reynolds number based on cascade exit velocity is $5.3 \times 10^{5}$. Two different coolants (air and $\mathrm{CO}_{2}$ ) were used to simulate coolant density effect. Coolant blowing ratio was varied between 0.8 and 1.2 for air injection and 0.4-1.2 for $\mathrm{CO}_{2}$ injection. Results show that film injection promotes earlier laminar-turbulent boundary layer transition on the suction surface and also enhances local heat transfer coefficients (up to $80 \%$ ) downstream of injection. An increase in coolant blowing ratio produces higher heat transfer coefficients for both coolants. This effect is stronger immediately downstream of injection holes. Film effectiveness is highest at a blowing ratio of $\mathbf{0 . 8}$ for air injection and at a blowing ratio of 1.2 for $\mathrm{CO}_{2}$ injection. Such detailed results will help provide insight into the film cooling phenomena on a gas turbine blade.

Received in final form on 10 July 2001.

This paper was prepared with the support of the NASA-Lewis Research Center under grant number NAG3-1656. The NASA technical team is Dr. Philip E. Poinsatte and Dr. Raymond Gaugler. Their support is greatly appreciated.

Address correspondence to Srinath V. Ekkad, Mechanical Engineering Dept., Louisiana State University, Baton Rouge, LA 70803. E-mail: ekkad@me.lsu.edu
Keywords Turbine blade, Film cooling, Heat transfer, Film effectiveness

\section{INTRODUCTION}

In modern gas turbines, sophisticated cooling techniques are employed to cool the components from high temperature combustion gases. Some turbine blades are cooled by ejecting cooler air from within the blade through discrete holes to provide a protective film on the surface exposed to hot gas path. Many studies have presented heat transfer measurements on turbine blades with film cooling. Nirmalan and Hylton (1990) and Camci and Arts (1990) studied heat transfer coefficients on film-cooled turbine blades. Takeishi et al. (1992) compared the film effectiveness values for a stationary cascade with mainstream turbulence intensity under $4 \%$ and for a rotor blade using the heat-mass transfer analogy. Ito et al. (1978) and Haas et al. (1992) studied the effect of coolant density on film effectiveness on turbine blades under low mainstream turbulence levels. Ito et al. (1978) found that an increase in coolant-to-mainstream density ratio causes an increase in film effectiveness on both pressure and suction surfaces for a blowing ratio of 1.0. Haas et al. (1992) found that their results show the same trends as that of Ito et al. (1978). They reported that an increase in coolant density for a low blowing ratio of 0.5 causes a decrease in film effectiveness on the suction surface. However, an increase in coolant density causes an increase in film effectiveness at higher blowing ratios. Abhari and Epstein (1994) conducted heat transfer experiments on a film-cooled transonic turbine stage in a short duration turbine facility. They measured steady and time-resolved chord-wise heat flux distributions at three spanwise locations. They concluded that film cooling reduces the time-averaged heat transfer by about $60 \%$ on the suction surface compared to the uncooled rotor blade. However, the film cooling effect on timeaveraged heat transfer is relatively low on the pressure surface. 
Ou et al. (1994) and Mehendale et al. (1994) simulated unsteady wake conditions over a linear turbine blade cascade with film cooling. They studied the effect of unsteady wakes on a model turbine blade with multiple-row film cooling using air and $\mathrm{CO}_{2}$ as coolants. They measured heat transfer coefficients and film effectiveness at discrete locations using thin foil heating and multiple thermocouples. Ou et al. (1994) reported that an increase in blowing ratio causes an increase in surface heat transfer coefficients, except in the transition region. They also reported the effect of coolant density on pressure and suction surface heat transfer coefficients. Mehendale et al. (1994) reported that a blowing ratio of 1.2 provides highest effectiveness for $\mathrm{CO}_{2}$ injection and a blowing ratio of 0.8 provides highest effectiveness for air injection. In the present study, detailed heat transfer coefficient and film effectiveness distributions are obtained in the near film hole region and over the entire blade surface using a transient liquid crystal technique. Such detailed distributions were not obtained by the previous studies using thin-foil-thermocouple measurement technique.

A few previous studies have measured detailed heat transfer coefficients on turbine blades without film cooling. MartinezBotas et al. (1995) presented detailed heat transfer coefficient distributions on a non-film cooled blade in an annular transonic cascade using a transient liquid crystal technique. Hoffs et al. (1997) measured heat transfer coefficients in a linear cascade without film cooling using a transient liquid crystal technique and compared the results with measurements using the naphthalene sublimation mass transfer technique. Du et al. (1997) presented detailed heat transfer coefficient distributions for a turbine blade without film cooling using the transient liquid crystal technique. They studied the effects of upstream unsteady wakes with trailing edge coolant ejection at various free-stream turbulence conditions. Other studies such as Vedula and Metzger (1991) and Ekkad et al. (1997a, b) presented detailed heat transfer coefficient and film effectiveness distributions for film cooling on a flat surface with a single row of simple-angle or compoundangle holes. They used a transient liquid crystal technique for detailed heat transfer coefficient and film effectiveness measurement.

The present study uses a similar transient liquid crystal technique (Vedula and Metzger, 1991; Ekkad et al., 1997a, b; Du et al., 1997) to measure detailed heat transfer coefficients and film effectiveness on a film-cooled turbine blade with air and $\mathrm{CO}_{2}$ injection. The present study presents detailed heat transfer coefficient and film effectiveness measurements on a blade under steady, low-turbulence flow conditions. This will help isolate the film cooling effect on the blade surface heat transfer distributions.

\section{EXPERIMENTAL APPARATUS}

Figure 1 shows the schematic of the test section and camera locations. The test apparatus consists of a low-speed wind tunnel with a suction-type blower. The five-blade linear cascade
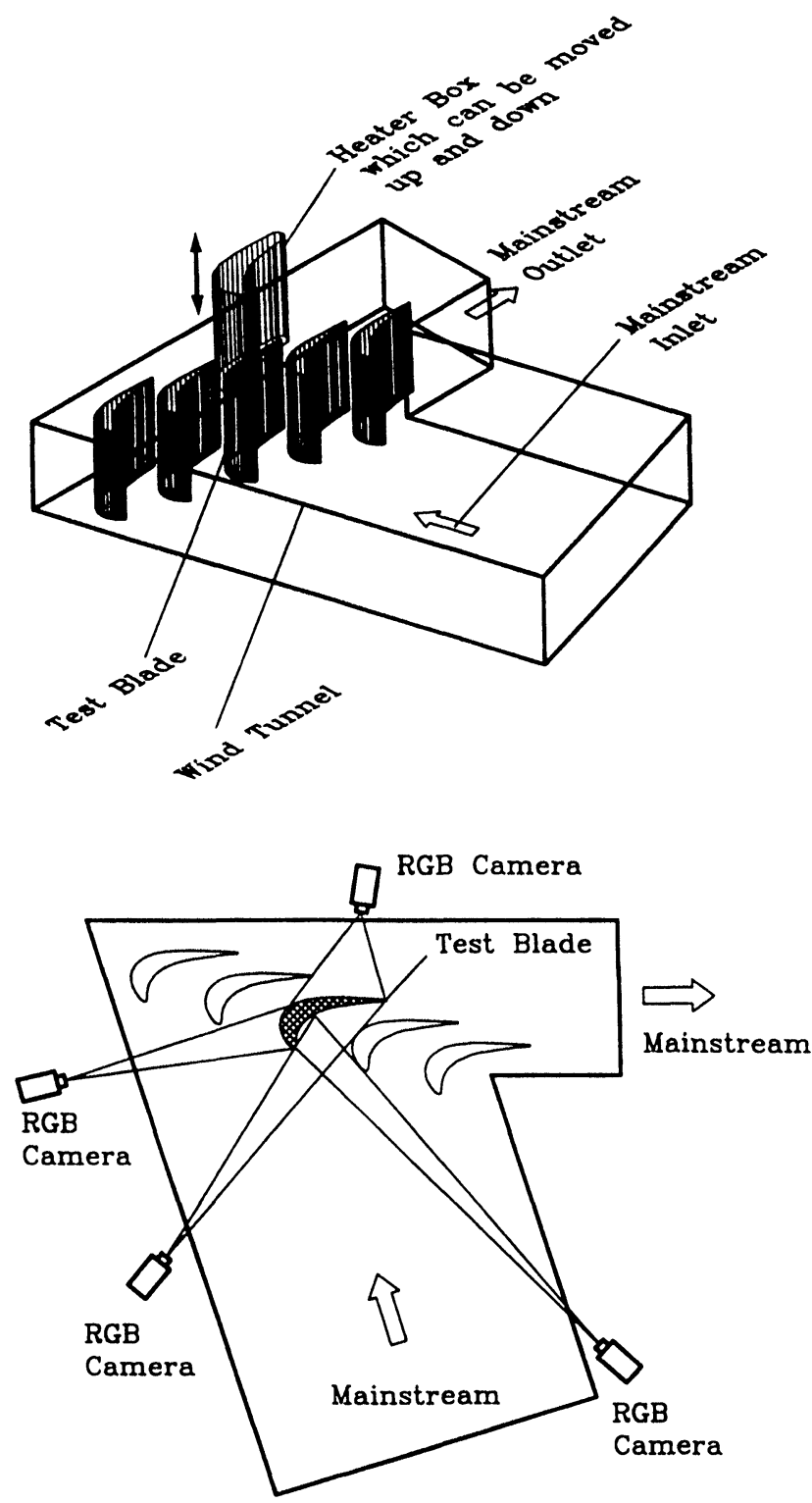

FIGURE 1

Schematic of test section and camera arrangement.

is shown in the figure. The mainstream turns $107.49^{\circ}$ and the flow is accelerated 2.5 times from inlet to exit of the cascade. The test apparatus is described in detail by Ou et al. (1994). A heater box, shown in the figure, is used to preheat the middle test blade prior to the transient test. The same blade is coated with a thin layer of thermochromic liquid crystals. The blade surface color changes during the transient test are analyzed using a high-speed, high-resolution image processing system. The image processing system consists of four cameras individually connected to a color frame grabber board inside the $\mathrm{PC}$. The cameras are focused using a color monitor. Commercial software is used to digitize the liquid crystal color changes. During a transient test, only one camera is operational. Since the color changes are processed real time and no frames are stored 
in the PC, the frame speed will be reduced if all the four cameras are operated at the same time. Hence, four separate tests are required to map the entire blade surface using four different camera locations as shown in the figure. Details on the image processing system are presented by Du et al. (1996).

Each blade in the linear cascade has an axial chord length of $17 \mathrm{~cm}$ and radial span of $25.2 \mathrm{~cm}$. The blade-to-blade spacing is $17.01 \mathrm{~cm}$ at the cascade inlet and the blade span-to-throat ratio is 5 . The blade configuration, scaled up five times, produces a velocity distribution typical of an advanced high-pressure turbine blade row. Figure 2 presents a section of the film-cooled turbine blade model. The coolant is supplied to various locations on the blade surface through five cavities. The first cavity supplies coolant to the three leading edge film hole rows and each of the other four cavities supply coolant to each row on the pressure and suction surfaces. Coolant is fed into each cavity from the bottom of the blade and flow rate into each cavity is controlled using a flowmeter. The coolant flow from each flowmeter is passed through a solenoid-controlled three-way diverter valve before the flow enters the coolant cavity inside the blade. Each solenoid-controlled valve is connected to a switch that triggers the coolant flow into the cavities at the instant the transient test is initiated. The blade film hole row geometry and configuration are shown in the figure. Figure 2 also presents a three-dimensional view of the pressure and suction surfaces of the test blade. The liquid crystal coated surface area is $15.2 \mathrm{~cm}$ wide and the data acquiring area is $7.6 \mathrm{~cm}$ wide along the midspan region of the test blade.

The new addition in this experiment compared to previous studies (Ou et al., 1994; Mehendale et al., 1994) is the heater box. The transient test requires that the blade be heated to a temperature higher than the liquid crystal color range $\left(37.2^{\circ} \mathrm{C}\right)$. During the transient test, the hot blade surface is suddenly cooled by exposing it to a cooler mainstream flow. The heater box has the blade profile and is slightly larger than the test blade. A gap of $10 \mathrm{~mm}$ exists between the blade outside surface and the heater box inner surface. The insides of the heater box are instrumented with thin foil heaters and controlled using several variacs to provide a near uniform blade surface temperature. The heater box is lowered to completely cover the test blade during heating. The blade surface temperature is monitored using embedded thermocouples during heating. The uniformity of surface temperature with heating is within $\pm 1.2^{\circ} \mathrm{C}$. An interpolation scheme was used to further reduce the temperature variation in the initial surface temperature to within $\pm 0.2^{\circ} \mathrm{C}$. When the surface is heated to the required uniform temperature, the suction type blower is switched on. The mainstream reaches full flow within 20-30 seconds. Once the mainstream has reached required flow, the heater box is lifted up completely to expose the test blade to the mainstream. The coolant flow and the image processing system are automatically triggered at the same instant the test surface is exposed to the mainstream. The color changes during the transient test are monitored by the system. The times of color change on the blade surface from colorless to
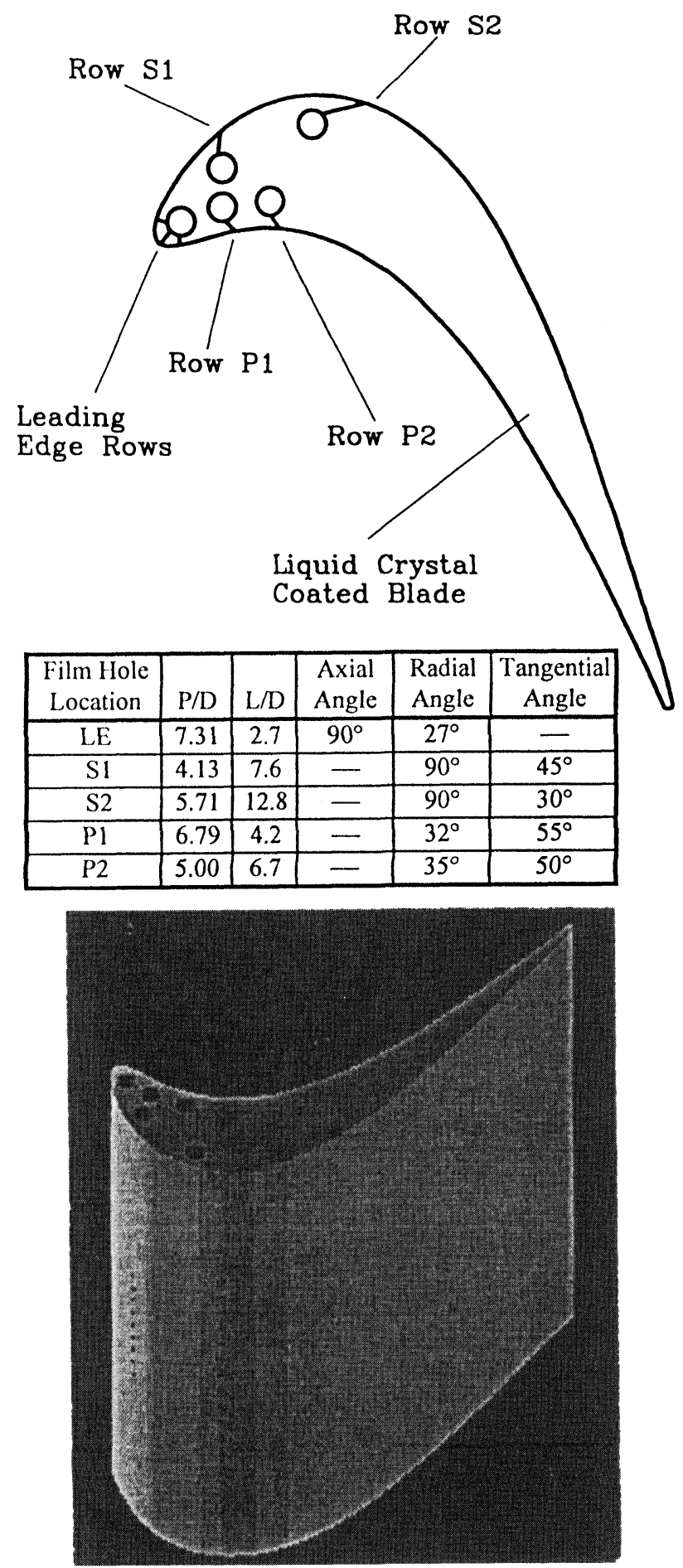

FIGURE 2

Test blade with film injection holes.

red at every pixel location is measured. Wide band liquid crystals (Hallcrest: R32C5W) were used for surface temperature measurements. However, in the present experiment, only the greento-red color transition point $\left(32.7^{\circ} \mathrm{C}\right)$ in the liquid crystal band is analyzed. 


\section{DATA ANALYSIS}

A transient liquid crystal technique was used to measure the detailed heat transfer coefficients and film effectiveness on the blade surface. The technique is similar to the one described by Vedula and Metzger (1991) and Ekkad et al. (1995a, b). A one-dimensional transient conduction model into a semi-infinite solid with convective boundary condition is assumed. The solution for surface temperature is obtained as

$$
\frac{T_{w}-T_{i}}{T_{m}-T_{i}}=\left[1-\exp \left(\frac{h^{2} \alpha t}{k^{2}}\right) \operatorname{erfc}\left(\frac{h \sqrt{\alpha t}}{k}\right)\right]
$$

where $T_{w}$ is the wall temperature when liquid crystals change to red from green $\left(32.7^{\circ} \mathrm{C}\right)$ at time $\mathrm{t}, T_{i}$ is the initial surface temperature, $T_{m}$ is the oncoming mainstream flow temperature, and $\alpha$ and $k$ are the thermal diffusivity and conductivity of the blade material respectively. The heat transfer coefficient is obtained from Equation (1). For film cooling tests, the local film temperature $\left(T_{f}\right)$ which is a mixture of the coolant $\left(T_{c}\right)$ and mainstream temperatures replace the mainstream temperature $\left(T_{m}\right)$ in Equation (1). The film temperature is defined in terms of $\eta$, which is the film effectiveness:

$$
\eta=\frac{T_{f}-T_{m}}{T_{c}-T_{m}} \quad \text { or } \quad T_{f}=\eta T_{c}+(1-\eta) T_{m}
$$

For the film-cooling test, we obtain an equation similar to Equation (1)

$$
\begin{aligned}
\frac{T_{w}-T_{i}}{T_{f}-T_{i}} & =\frac{T_{w}-T_{i}}{\eta T_{c}+(1-\eta) T_{m}-T_{i}} \\
& =\left[1-\exp \left(\frac{h^{2} \alpha t}{k^{2}}\right) \operatorname{erfc}\left(\frac{h \sqrt{\alpha t}}{k}\right)\right]
\end{aligned}
$$

Two similar transient tests are run to obtain the heat transfer coefficient $(h)$ and film effectiveness $(\eta)$. In the first test, the blade surface is heated and the coolant and mainstream temperatures are nearly the same. In this case, there is only one unknown, $h$, in the equation. For the second test, the coolant is heated to a temperature close to blade initial temperature. The calculated local heat transfer coefficient from the first test is substituted in the equation to obtain the local film effectiveness. The above equation is solved at each point (57,760 points) on the blade surface to obtain the detailed heat transfer coefficient and film effectiveness distributions.

The average experimental uncertainty in the measurement of the local heat transfer coefficient $(h)$, based on Kline and McClintock's 1953 methodology, is about $\pm 5.7 \%$. The individual uncertainties of all the parameters in Equation (1) have been included: time of color change, $t: \pm 2.5 \%$; wall properties, $\alpha / k^{2}: \pm 4.0 \%$; mainstream temperature, $T_{m}: \pm 3.0 \%$; liquid crystal green temperature, $T_{w}: \pm 1.0 \%$; initial temperature of wall, $T_{I}: \pm 1.5 \%$; total uncertainty (root-sum-square method): $\pm 2.5 \%$.

The average uncertainty in the film effectiveness measurement includes the additional uncertainty in heat transfer coef-
TABLE I

Test conditions

\begin{tabular}{lclllll}
\hline Case no. & Re & Coolant & $M$ & $V R$ & $D R$ & $I$ \\
\hline 1 & $5.3 \times 10^{5}$ & None & & & & \\
2 & & $\mathrm{CO}_{2}$ & 0.4 & 0.27 & 1.5 & 0.11 \\
3 & & $\mathrm{CO}_{2}$ & 0.8 & 0.53 & 1.5 & 0.42 \\
4 & & $\mathrm{CO}_{2}$ & 1.2 & 0.8 & 1.5 & 0.96 \\
5 & & Air & 0.8 & 0.8 & 1.0 & 0.64 \\
6 & & Air & 1.2 & 1.2 & 1.0 & 1.44 \\
\hline
\end{tabular}

ficient measurement and was estimated to be about $\pm 5.9 \%$. It should be noted that the worst case uncertainty is in the immediate vicinity of the hole (less than 1-diameter around the hole) and close to the blade trailing edge where it could be as high as $\pm 17 \%$ due to invalidation of the semi-infinite model assumption. However, the semi-infinite solid assumption can be applied where thickness of material is higher than $0.51 \mathrm{~cm}$.

\section{RESULTS AND DISCUSSION}

Experiments were performed at a cascade exit Reynolds number of $5.3 \times 10^{5}$. The corresponding flow velocity at the cascade exit was $50 \mathrm{~m} / \mathrm{s}$. Two different coolants, air and $\mathrm{CO}_{2}$, are used to simulate coolant-to-mainstream density ratios of $D R=1.0$ and $D R=1.5$, respectively. Air as coolant was tested at blowing ratios of 0.8 and 1.2 and $\mathrm{CO}_{2}$ was tested at blowing ratios of 0.4 , 0.8 , and 1.2. The flow conditions for the film cooling tests are summarized in Table I. For all the results presented in this study, the oncoming free-stream turbulence intensity was measured to be about $0.75 \%$ at the cascade inlet.

\section{Flow Measurement}

Figure 3 presents the local-to-exit velocity ratio $\left(V / V_{2}\right)$ distribution around the blade. A pressure tap instrumented blade was used to measure the surface static pressure distributions which were then converted to local mainstream velocity distribution around the blade (Ou et al., 1994). The flow is accelerated significantly on the suction surface from leading edge to about $50 \%$ of the suction surface, after which the velocity decreases a little toward the trailing edge. On the pressure surface, the flow accelerates a little with a sudden increase in velocity just downstream of the leading edge to about $X / P L=0.05$. The flow then stays constant till $X / P L=0.15$ and then accelerates gradually toward the trailing edge. The pressure-tap-instrumented blade is of same profile as the heat transfer blade but does not have film holes. The prediction shown in Fig. 3 was calculated by GE's in-house code.

\section{Film Cooling Measurement \\ Effect of Blowing Ratio}

Figure 4 presents the detailed Nusselt number distributions on the blade suction and pressure surfaces for $\mathrm{CO}_{2}$ injection and blowing ratios of $0.4,0.8$, and 1.2. Case 1 is for a no-film hole 


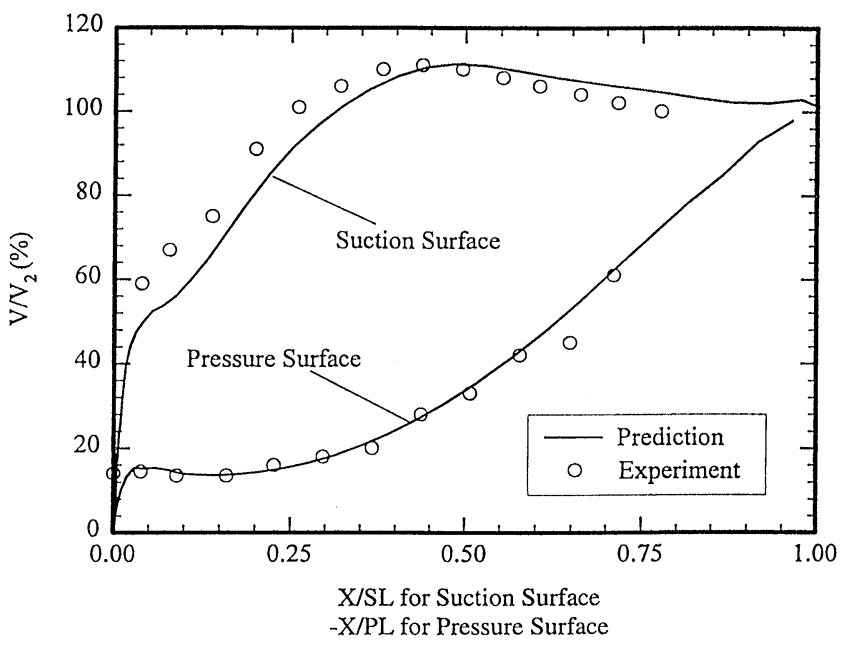

FIGURE 3

Local-to-exit velocity ratio $\left(V / V_{2}\right)$ distributions on the test blade surface.

blade; case 2 is for $M=0.4$; case 3 is for $M=0.8$; case 4 is for $M=1.2$ for a blade with film holes. The blades with and without film cooling holes have the same shape and flow angles. The blades are also made from the same material (Ren Shape).

Effect on suction surface. The no-film hole surface Nusselt number (case 1) levels drop significantly from the leading edge with increasing streamwise distance on the suction surface. Nusselt numbers are lowest around $X / S L=0.5$, after which the Nusselt numbers increase again. This is due to boundary layer transition to turbulence. Nusselt numbers are higher toward the trailing edge, as the transition is not complete. For a film cooled blade (case 2) with $M=0.4$, Nusselt number show streaks due to film cooling jets downstream of leading edge holes. High Nusselt numbers immediately downstream of injection decrease rapidly and the jet effect is nonexistent upstream of the first film hole row on the suction surface $(\mathrm{S} 1)$. Downstream of the row $\mathrm{S} 1$, jet streaks of higher Nusselt numbers are obtained along the holes. The streaks extend all the way up to the next film hole row S2. However, the jets do not cause any Nusselt number enhancement between the holes for row $\mathrm{S} 1$. Downstream of film hole row $\mathrm{S} 2$, the Nusselt numbers are significantly higher than for case 1 . Some streaks of high Nusselt numbers are obtained along the holes. Such high levels of Nusselt number downstream of row S2 may be explained. Film injection may cause boundary layer instabilities, which cause earlier laminar-turbulent boundary layer transition. This may produce higher heat transfer coefficients of up to $80 \%$ higher downstream of injection. After completion of transition, the effect of coolant jets disappears and the Nusselt numbers are not affected by blowing ratio. Nusselt numbers decrease after transition with the growth of the turbulent boundary layer. The streaks downstream of hole row S1 become stronger and appear to mix downstream with hole row S2. The effect of blowing ratio after hole row $\mathrm{S} 2$ is to increase the Nusselt number slightly. With an increase in blowing ratio, the jet-mainstream

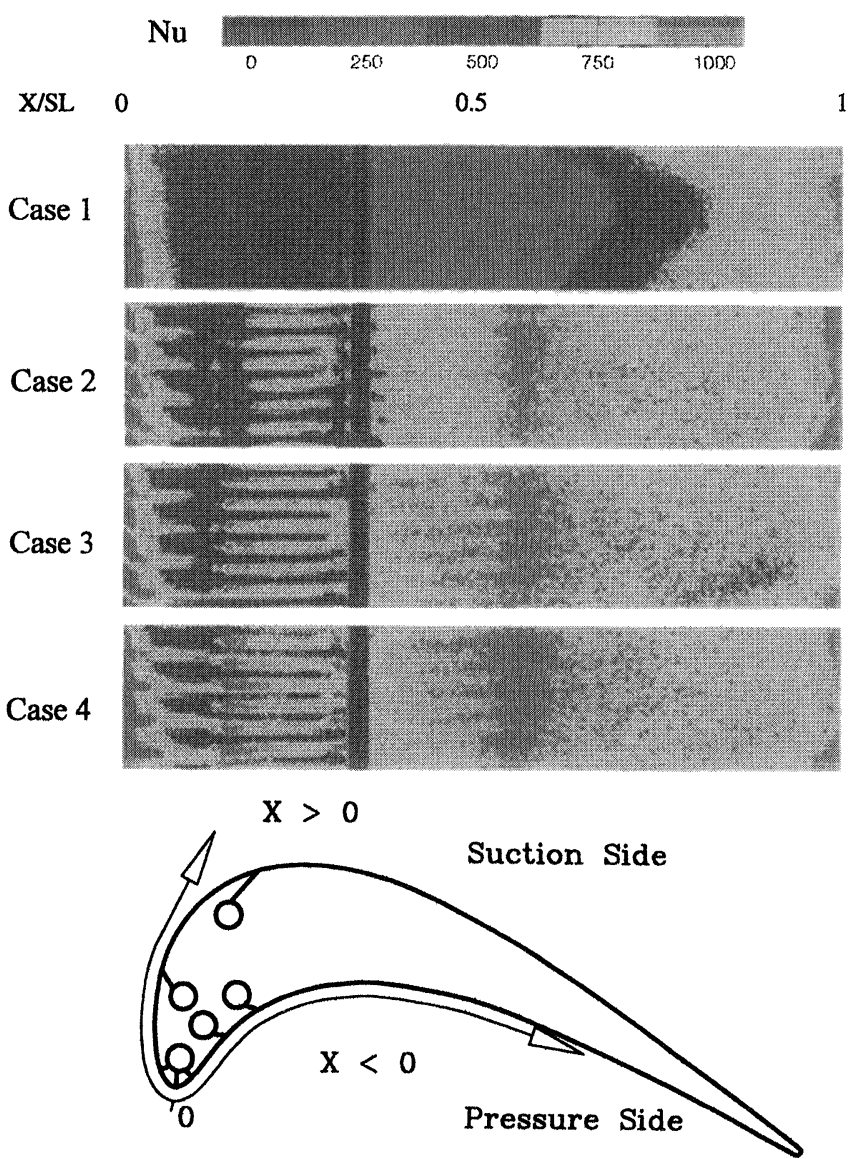

Case 1

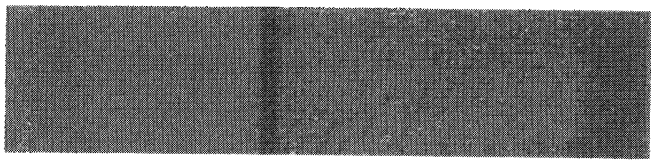

Case 2

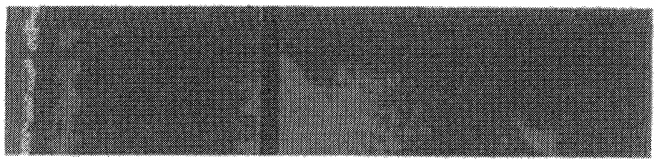

Case 3

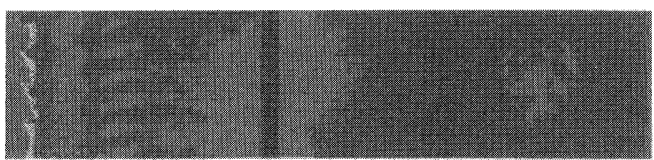

Case 4

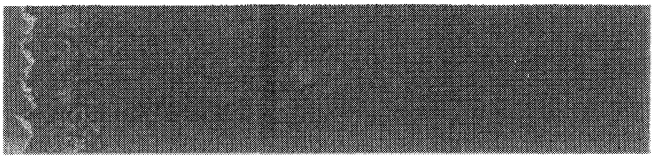

$\mathrm{X} / \mathrm{PL} \quad 0$

$$
-0.5
$$

FIGURE 4

Effect of blowing ratio on detailed Nusselt number distributions for $\mathrm{CO}_{2}$ injection.

interaction increases causing more turbulence downstream. This may be the cause for higher Nusselt numbers with an increase in blowing ratio immediately downstream of injection.

Effect on pressure surface. For case 1, the Nusselt numbers drop rapidly till $X / P L=-0.15$ and then increase a little bit 
over the entire surface. For case 2 , film injection has a very small effect immediately downstream of leading edge row injection. However, Nusselt numbers are enhanced between the leading edge row and first row P1 compared to case 1. Downstream of rows $\mathrm{P} 1$ and $\mathrm{P} 2$, film injection enhances Nusselt numbers up to $60 \%$ over case 1 . The effect of film injection on the pressure surface is more in the region immediately downstream of injection. Since the boundary layer on the pressure surface is thicker than on the suction surface, the effect on Nusselt numbers due to film injection is reduced. Jet streaks are not evident on the pressure surface. With further increases in blowing ratio from $M=0.4$ to $M=1.2$, Nusselt numbers are not significantly affected. The increase in injectant mass into a thicker boundary layer does not appear to disturb the boundary layer as significantly as in the case of the thinner boundary layer on the suction surface.

Nusselt numbers with film injection are significantly enhanced due to the boundary layer disturbance cause by injection. Earlier studies on film cooling have shown that film injection can create local turbulence intensities as high as $15-20 \%$ depending on the blowing ratio. With such high local turbulence, heat transfer coefficients downstream of injection are significantly enhanced as seen in the figure.

Figure 5 presents the span-averaged Nusselt number distribution for cases $1-4$. The Nusselt number distributions for case 1 are the lowest on both pressure and suction surfaces. Laminarturbulent boundary layer transition on suction surface occurs at about $X / S L=0.55$. Nusselt numbers are enhanced significantly with addition of film injection (case 2-4). As explained earlier, film injection disturbs the boundary layer and causes earlier transition to a turbulent boundary layer. Higher Nusselt numbers are obtained downstream of injection row S1. Further increase in Nusselt numbers occurs with transition and addition of coolant at row S2. On the pressure surface, film injection produces higher heat transfer coefficients from leading edge in-

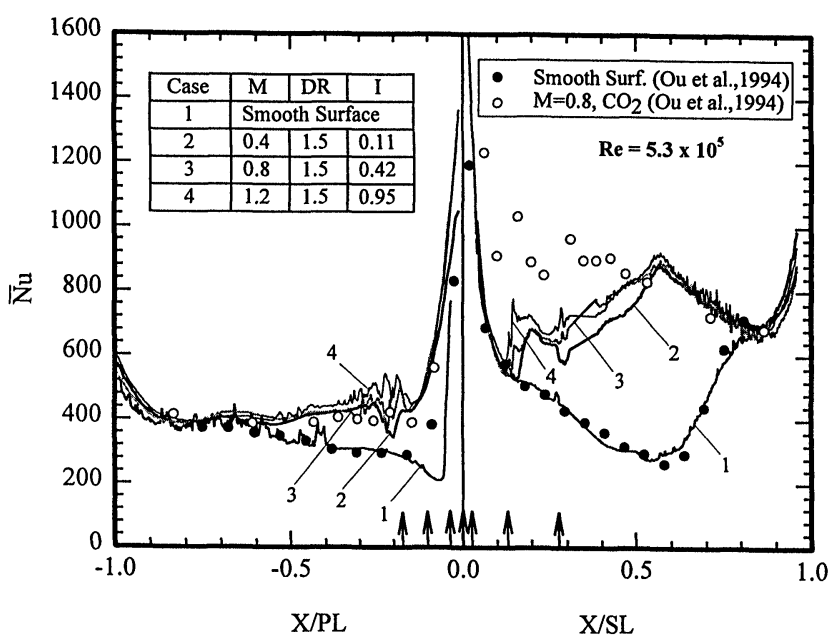

FIGURE 5

Effect of blowing ratio on span-averaged Nusselt number distributions for $\mathrm{CO}_{2}$ injection. jection location to downstream of hole row P2. Higher blowing ratio produces higher Nusselt numbers downstream of injection for both pressure and suction surfaces.

The present results are compared to results for the same cases from Ou et al. (1994). The results for the no-film holes blade are in good agreement with the present data. Ou et al. (1994) show much higher Nusselt numbers downstream of injection holes on the suction surface. However, the pressure surface Nusselt numbers with film injection are in good agreement with present results. There may be two reasons for the differences in the results. The study by Ou et al. (1994) had the same coolant cavity feeding the hole rows P2 and S2. This may cause more coolant to exit out of hole row $\mathrm{S} 2$ and causing higher heat transfer coefficients. The pressure surface results are closer for both studies, as the blowing ratio does not have a significant effect on Nusselt numbers as compared to the suction surface. However, in the present study, two different cavities feed coolant to the hole rows. This may explain the lower Nusselt numbers obtained on the suction surface. Also, it is difficult to estimate the heat loss to the coolant during the steady state test by Ou et al. Since the heat loss to coolant was not estimated, that could add to the error. Ou et al. (1994) measured four thermocouple locations in the spanwise direction at every axial location.

Figure 6 presents the detailed film effectiveness distributions for cases 2, 3, and 4.

Effect on suction surface. For case 2, film effectiveness immediately downstream of leading edge holes is as high as $0.5 \mathrm{but}$ drops rapidly. The coolant protection dissipates rapidly in this high-curvature region as the jets do not adhere to the surface. High effectiveness is observed downstream of row $\mathrm{S} 1$ along the holes. The high film effectiveness streaks extend up to the next hole row S2. However, the film effectiveness between the holes is lower due to lack of spanwise mixing of jets. Effectiveness downstream of injection from row $\mathrm{S} 2$ shows shorter streaks with the jets coalescing downstream. The high curvature of the blade and the boundary layer transition to turbulence in this region (Fig. 4) may be the reason for the shorter streaks. As the blowing ratio increases from $M=0.4$ to $M=1.2$, film effectiveness downstream of each injection hole row increases. Effectiveness is higher downstream of leading edge hole rows with short jet streaks. The effectiveness is significantly higher downstream of row S1 along the hole centerline. The streaks of high effectiveness are stronger and appear to mix with downstream row S2. Downstream of S2 also, the effectiveness is higher. As blowing ratio increases, more coolant is injected into the mainstream providing more protection to the surface. The effectiveness is as high as 0.2 at about $X / S L=0.6$ for $M=1.2$.

Effect on pressure surface. Effectiveness distributions on the pressure surface do not show as strong jet-like streaks as on the suction surface. Effectiveness levels are also not very high downstream of injection holes. As the blowing ratio increases, film effectiveness in the entire injection region increases due to increased amounts of coolant injected into the boundary layer. There is lesser interaction between coolant and mainstream on 


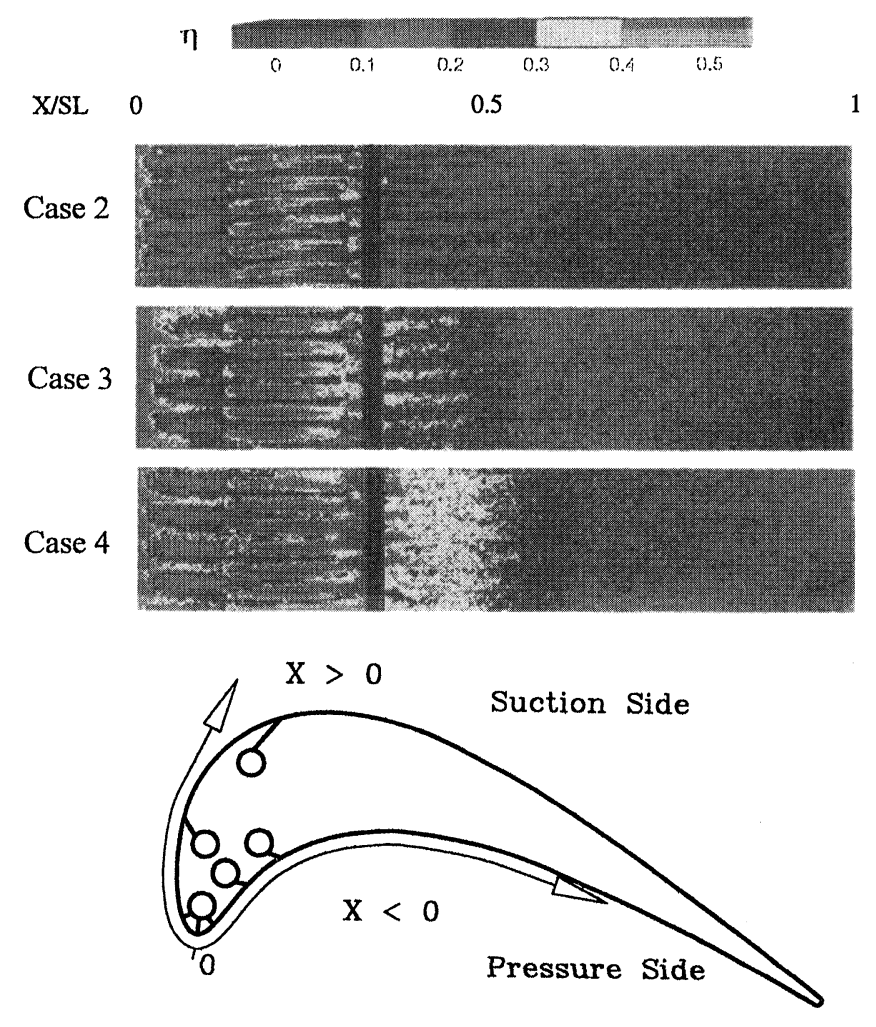

Case 2

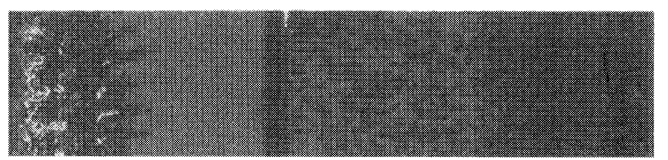

Case 3

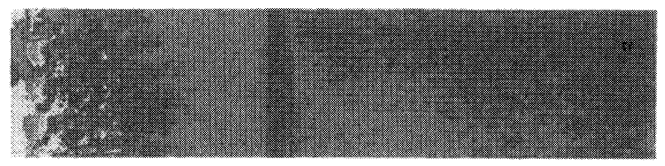

Case 4

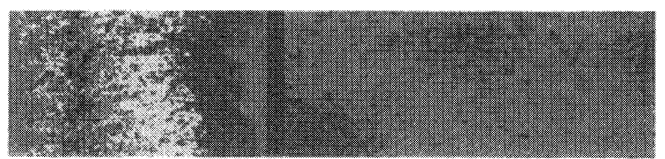

$\mathrm{X} / \mathrm{PL} \quad 0$

$-0.5$

$-1$

FIGURE 6

Effect of blowing ratio on detailed film effectiveness distributions for $\mathrm{CO}_{2}$ injection.

the pressure surface due to the thicker boundary layer. The effect is significant downstream of LE holes. Effectiveness also increases around injection hole rows $\mathrm{P} 1$ and $\mathrm{P} 2$ with values up to 0.4 . Higher blowing ratio for $\mathrm{CO}_{2}$ injection produces higher effectiveness on the blade surface.

Figure 7 presents the span-averaged film effectiveness distributions for cases 2-4. Effectiveness increases with an increase in the blowing ratio on the suction surface. Effectiveness drops rapidly downstream of leading edge holes on the suction surface, then increases immediately downstream of hole row S1, drops again, and increases immediately downstream of hole row

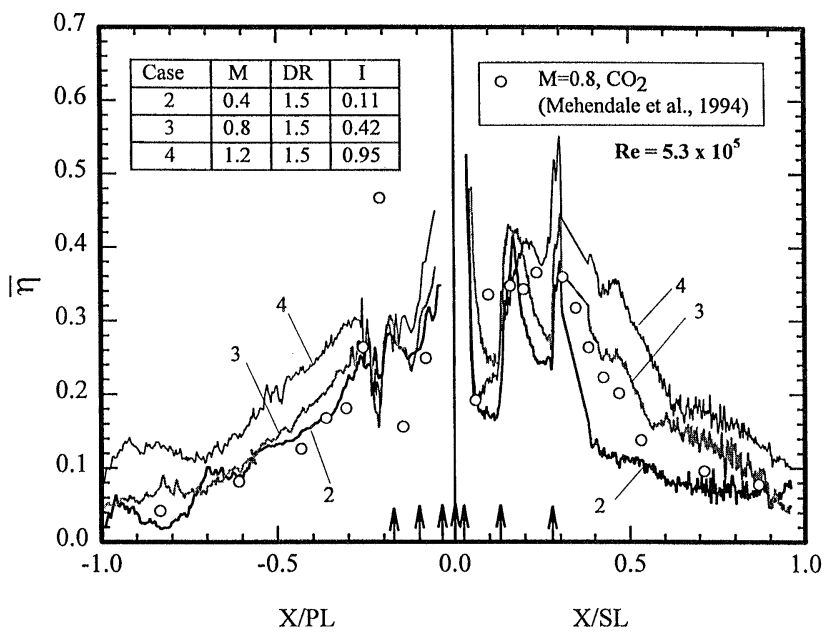

FIGURE 7

Effect of blowing ratio on span-averaged film effectiveness distributions for $\mathrm{CO}_{2}$ injection.

S2 and then decreases gradually toward the trailing edge for all three blowing ratios. High effectiveness is obtained downstream of each row of holes. However, the effect of coolant injection decreases rapidly further downstream of each row. Results from Mehendale et al. (1994) for the same coolant and flow conditions are also presented at $M=0.8$. The data are comparable away from the injection holes. However, in the injection region, there are differences in the measured effectiveness levels between the studies. The reason for this could be similar to the reason explained for heat transfer coefficient data.

\section{Effect of Coolant Density}

Figure 8 presents effect of coolant density on span-averaged Nusselt number distributions for $M=0.8$ and $M=1.2$ (cases

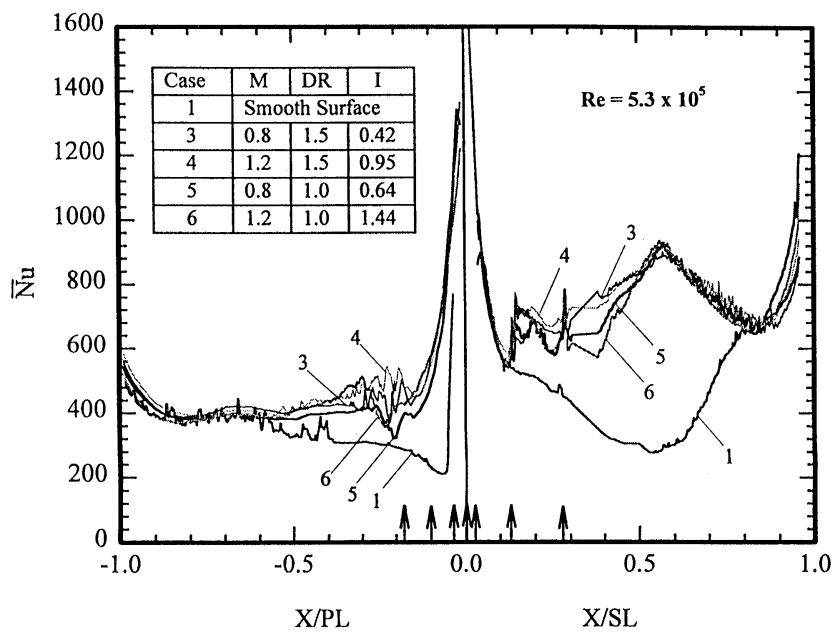

FIGURE 8

Effect of coolant density on span-averaged Nusselt number distributions. 


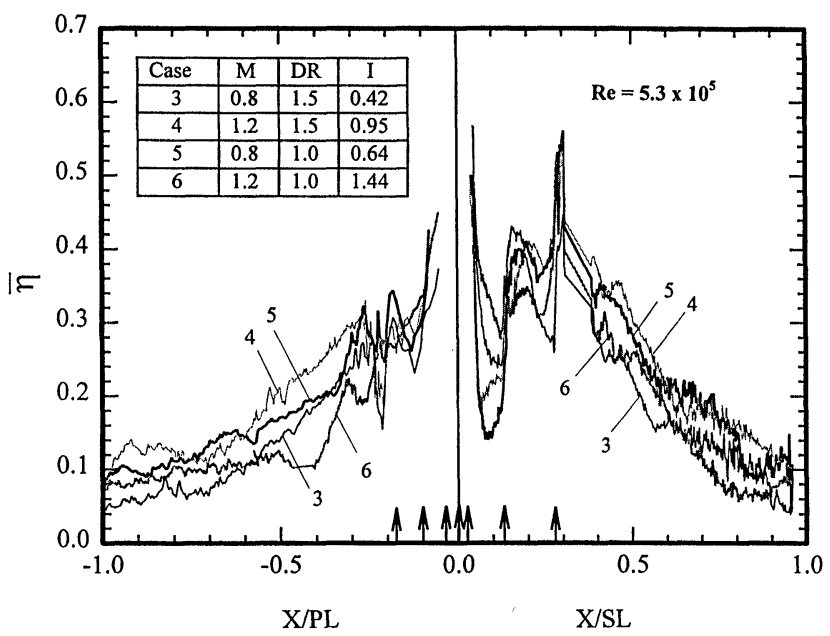

FIGURE 9

Effect of coolant density on span-averaged film effectiveness distribution.

$2-4,5-6)$. Air injection simulates a density ratio of 1.0 whereas $\mathrm{CO}_{2}$ injection simulates a density ratio of 1.5 . Film injection causes earlier boundary layer transition on the suction surface and enhances the Nusselt numbers over the entire surface, as indicated earlier. Effects of coolant density are limited to regions downstream of injection holes. Higher density coolant produces higher Nusselt numbers downstream of injection at the same blowing ratio. This effect is stronger on the suction surface. On the pressure surface, the density ratio effect vanishes immediately downstream of injection. Change in coolant density ratio has only a small effect on the already high Nusselt numbers produced by film injection.

Figure 9 presents the span-averaged film effectiveness distributions for the same cases as for Fig. 8. Film effectiveness on the suction surface is higher for $\mathrm{CO}_{2}$ injection at $M=1.2$. At a lower blowing ratio of $M=0.8$, air provides higher effectiveness than $\mathrm{CO}_{2}$ injection. At low blowing ratio of 0.8 , air has higher momentum $(I=0.64)$ compared to $\mathrm{CO}_{2}(I=0.42)$ and protects the surface better. Higher momentum injection does not diffuse into the mainstream as rapidly as that for lower momentum injection and thus provides increased effectiveness. At $M=1.2$, air possesses very high momentum $(I=1.44)$ and coolant jets blow into the mainstream penetrating the boundary layer and do not provide good protection compared to $\mathrm{CO}_{2}$ injection $(I=$ $0.96)$. Overall, $\mathrm{CO}_{2}$ injection at $M=1.2$ provides highest effectiveness downstream of injection. But in the injection hole region, it is difficult to distinguish the blowing ratio and density ratio effects.

Figure 10 presents the effect of coolant-to-mainstream momentum flux ratio $(I)$ on span-averaged Nusselt number ratios and film effectiveness values at three streamwise locations. All the locations shown in the figure are in the region between hole rows $\mathrm{S} 1$ and $\mathrm{S} 2$. The hole row $\mathrm{S} 1$ is at $X / S L=1.2$ and hole row

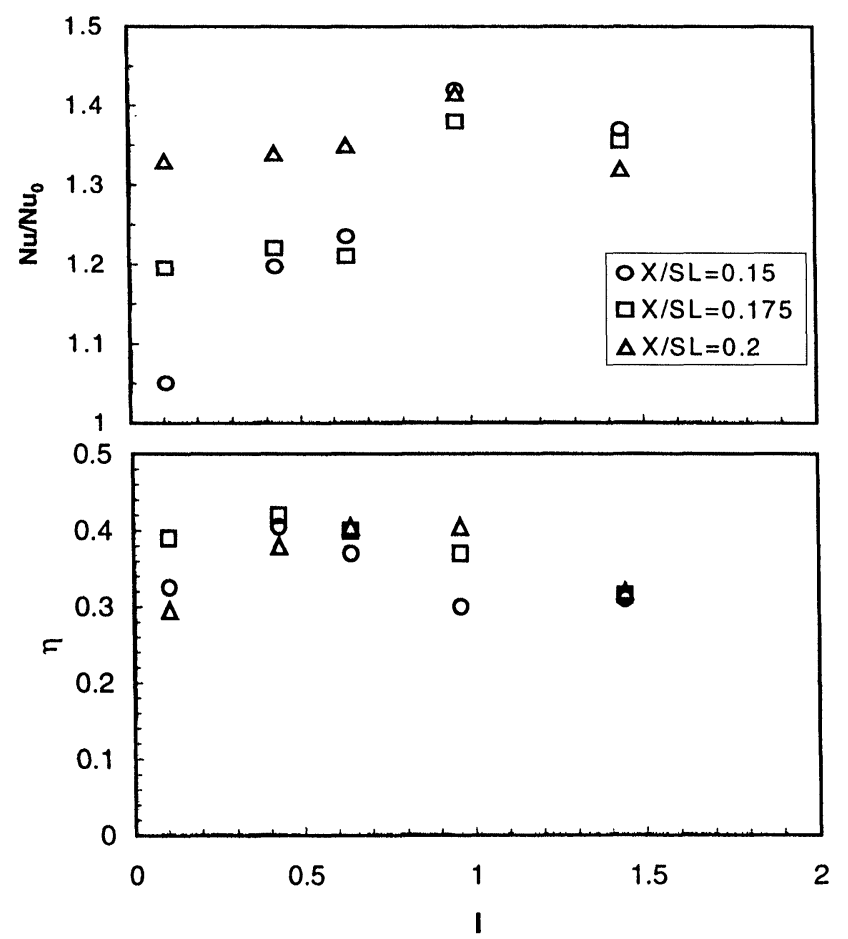

FIGURE 10

Effect of coolant-to-mainstream momentum flux ratio $(I)$ on spanwise averaged Nusselt number ratio $\left(N u / N u_{0}\right)$ and film effectiveness values at three axial locations between hole rows S1 and S2.

$\mathrm{S} 2$ is at $X / S L=0.28$. The overall averaged values for the entire pressure or suction surface distributions are not considered here due to the presence of multi-row injections. This figure is an attempt to capture the behavior of the heat transfer coefficient and film effectiveness under varying film cooling flow conditions. The Nusselt number ratio is obtained by dividing the film-cooled blade Nusselt number with a no-holes blade Nusselt number. Results show that Nusselt number ratio increases with increasing $I$ values (with highest values at $I=1.0$ ) and then begin to decrease. It is difficult to make any conclusions for high $I$ values as this study only investigates one $I$ value over 1.0 . It appears that the location effect is significant for lower $I$ values, with the location closest to the hole providing lowest Nusselt number ratio. The coolant at lower momentum flux ratios tends to stay closer to the surface after injection and mixes less with the mainstream, providing lower heat transfer coefficients. However, farther away from the hole, the mainstream breaks down the jet structures and thus causes higher heat transfer coefficients. Blade curvature effect may also be significant at lower $I$ values. For higher I values, the location's effect on Nusselt number ratio is reduced. Film effectiveness values show considerably lower effect of location from the hole. Highest effectiveness occurs around $I=0.5$. Effectiveness decreases at larger $I$ values due to jet lift-off. 


\section{CONCLUSIONS}

Detailed Nusselt number and film effectiveness distributions on a turbine blade with film cooling were presented under the effects of coolant blowing ratio and density ratios. Results were obtained at a cascade exit Reynolds number of $5.3 \times 10^{5}$. Film injection was provided through three rows on the leading edge and two rows each on the pressure and suction surfaces.

1. Detailed Nusselt number and film effectiveness distributions using the transient liquid crystal technique were obtained on the entire blade midspan region. The strong spanwise and axial variations due to film injection are clearly evident in the detailed distributions that also provide valuable insight into the film cooling process.

2. Film injection causes earlier laminar-to-turbulent boundary layer transition on the suction surface. Film injection also increases spanwise and axial variations in Nusselt number distributions on the blade mid-span. Nusselt numbers on the suction surface are significantly enhanced for a blade with film injection compared to a blade without film holes. Pressure surface Nusselt numbers are also enhanced with film injection, but are not as significantly high as on the suction surface.

3. Higher film effectiveness values are observed downstream of injection holes on the suction surface. However, such high effectiveness values do not extend far downstream of injection on the pressure surface.

4. Nusselt numbers increase with an increase in blowing ratio, particularly in the region immediately downstream of holes. Film effectiveness significantly increases with an increase in blowing ratio for $\mathrm{CO}_{2}$ injection. Air produces higher effectiveness at a blowing ratio of 0.8 .

5. An increase in coolant density has little effect except in the regions immediately downstream of injection, where $\mathrm{CO}_{2}$ injection provides higher Nusselt numbers than air injection. Higher density coolant $\left(\mathrm{CO}_{2}\right)$ produces higher effectiveness at higher blowing ratios $(M=1.2)$. However, lower density coolant (air) provides higher effectiveness at lower blowing ratios $(M=0.8)$.

The local heat transfer coefficient and film effectiveness results can be combined to obtain the overall film cooling performance for each case. Such information was provided in an earlier study by Mehendale et al. (1994).

\section{NOMENCLATURE}

$C_{x} \quad$ blade axial chord length $(17 \mathrm{~cm})$

$D$ film hole diameter

$d \quad$ wake generator rod diameter

$D R$ coolant-to-mainstream density ratio, $\rho_{c} / \rho_{m}$

$h \quad$ local heat transfer coefficient

$I$ coolant-to-mainstream momentum flux ratio, $\rho_{c} V_{c}^{2} / \rho_{m} V^{2}$, $M^{2} / D R$

$k$ thermal conductivity of blade material $\left(0.159 \mathrm{~W} / \mathrm{m}-{ }^{\circ} \mathrm{C}\right)$ $k_{\text {air }} \quad$ thermal conductivity of mainstream air

$L \quad$ length of film injection hole

$M$ coolant-to-mainstream mass flux ratio or blowing ratio, $\rho_{c} V_{c} / \rho_{m} V$

$\mathrm{Nu}$ local Nusselt number based on axial chord, $h C_{x} / k_{\text {air }}$

$\mathrm{Nu}$ span-averaged Nusselt number

$P \quad$ film hole pitch

$P L \quad$ streamwise length on the pressure surface $(25.6 \mathrm{~cm})$

$R e$ Reynolds number based on exit velocity and axial chord, $V_{2} C_{x} / v$

$S L \quad$ streamwise length on the suction surface $(33.1 \mathrm{~cm})$

$t \quad$ liquid crystal color change time

$T_{c} \quad$ coolant temperature

$T_{i} \quad$ initial temperature of blade surface

$T_{m} \quad$ mainstream temperature

$T_{w} \quad$ liquid crystal color change temperature from green to red

$V \quad$ local mainstream velocity along the blade pressure or suction surface

$V_{1} \quad$ cascade inlet velocity

$V_{2}$ cascade exit velocity

$V_{c} \quad$ coolant hole exit velocity

$V R$ coolant-to-mainstream velocity ratio, $V_{c} / V$

$X \quad$ streamwise distance from blade leading edge

$\alpha \quad$ thermal diffusivity of blade material $\left(0.135 \times 10^{-6} \mathrm{~m}^{2} / \mathrm{s}\right)$

$\eta \quad$ local film effectiveness

$\bar{\eta} \quad$ span-averaged film effectiveness

$v \quad$ kinematic viscosity of mainstream air

$\rho_{c} \quad$ coolant density

$\rho_{m} \quad$ mainstream flow density

\section{REFERENCES}

Abhari, R. S., and Epstein, A. H., 1994, An Experimental Study of Film Cooling in a Rotating Transonic Turbine, ASME Journal of Turbomachinery, vol. 116, pp. 63-70.

Camci, C., and Arts, T., 1990, An Experimental Convective Heat Transfer Investigation Around a Film-Cooled Gas Turbine Blade, ASME Journal of Turbomachinery, vol. 112, pp. 497-503.

Du, H., Ekkad, S. V., and Han, J. C., 1997, Effect of Unsteady Wake with Trailing Edge Coolant Ejection on Detailed Heat Transfer Coefficient Distributions for a Gas Turbine Blade, ASME Journal of Heat Transfer, vol. 119, pp. 242-248.

Ekkad, S. V., Zapata, D., and Han, J. C., 1997a, Heat Transfer Coefficients Over a Flat Surface with Air and $\mathrm{CO}_{2}$ Injection Through Compound Angle Holes Using a Transient Liquid Crystal Image Method, ASME Journal of Turbomachinery, vol. 119, pp. 580-586.

Ekkad, S. V., Zapata, D., and Han, J. C., 1997b, Film Effectiveness Over a Flat Surface with Air and $\mathrm{CO}_{2}$ Injection Through Compound Angle Holes Using a Transient Liquid Crystal Image Method, ASME Journal of Turbomachinery, vol. 119, pp. 587-593.

Haas, W., Rodi, W., and Schönung, B., 1992, The Influence of Density Difference Between Hot and Coolant Gas on Film Cooling by a Row of Holes: Predictions and Experiments, ASME Journal of Turbomachinery, vol. 114, pp. 747-755.

Hoffs, A., Bolcs, and Harasagama, S. P., 1997, Transient Heat Transfer Experiments in a Linear Cascade Via an Insertion Mechanism 
Using a Liquid Crystal Technique, ASME Journal of Turbomachinery, vol. 119, pp. 9-13.

Ito, S., Goldstein, R. J., and Eckert, E. R. G., 1978, Film Cooling of a Gas Turbine Blade, ASME Journal of Engineering for Power, vol. 100, pp. 476-481.

Kline, S. J., and McClintock, F. A., 1953, Describing Uncertainties in Single Sample Experiments, Mechanical Engineering, vol. 75, pp. 3-8.

Martinez-Botas, R. F., Lock, G. D., and Jones, T. V., 1995, Heat Transfer Measurements in an Annular Cascade of Transonic Gas Turbine Blades Using a Transient Liquid Crystal Technique, ASME Journal of Turbomachinery, vol. 117, pp. 425-431.

Mehendale, A. B., Han, J. C., Ou, S., and Lee, C. P., 1994, Unsteady Wake Over a Linear Turbine Blade Cascade with air and $\mathrm{CO}_{2}$ Film Injection: Part II-Effect on Film Effective- ness and Heat Transfer Distributions, ASME Journal of Turbomachinery, vol. 116, pp. 730-737.

Nirmalan, V., and Hylton, L., 1990, An Experimental Study of Turbine Vane Heat Transfer with Leading Edge and Downstream Film Cooling, ASME Journal of Turbomachinery, vol. 112, pp. 477-487. Ou, S., Han, J. C., Mehendale, A. B., and Lee, C. P., 1994, Unsteady Wake Over a Linear Turbine Blade Cascade with air and $\mathrm{CO}_{2}$ Film Injection: Part I-Effect on Heat Transfer Coefficients, ASME Journal of Turbomachinery, vol. 116, pp. 721-729.

Takeishi, K., Aoki, S., Sato, T., and Tsukagoshi, K., 1992, Film Cooling on a Gas Turbine Rotor Blade, ASME Journal of Turbomachinery, vol. 114, pp. 828-834.

Vedula, R. J., and Metzger, D. E., 1991, A Simultaneous Determination of Local Effectiveness and Heat Transfer Distributions in ThreeTemperature Convection Situations, ASME Paper No. 91-GT-345. 

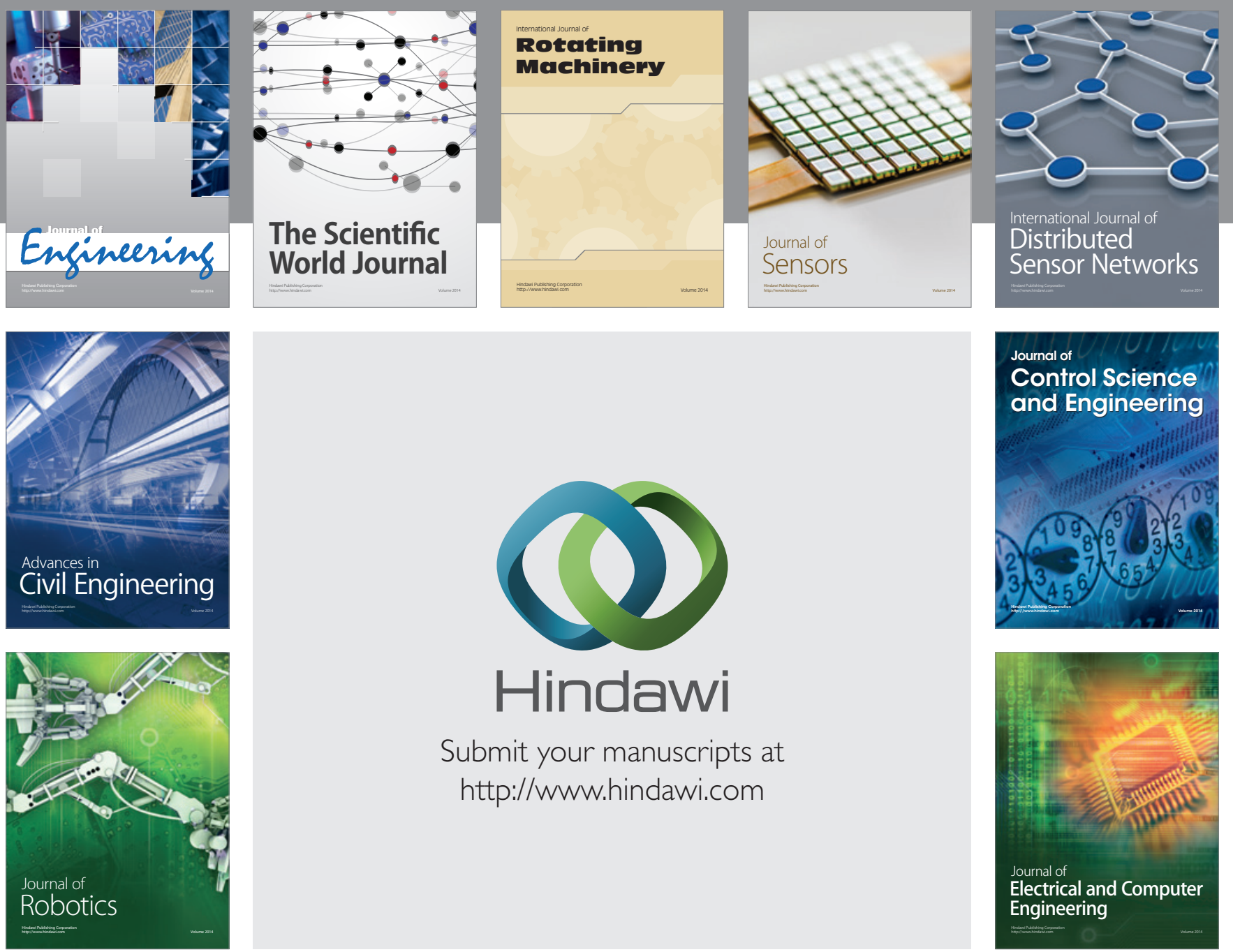

Submit your manuscripts at

http://www.hindawi.com
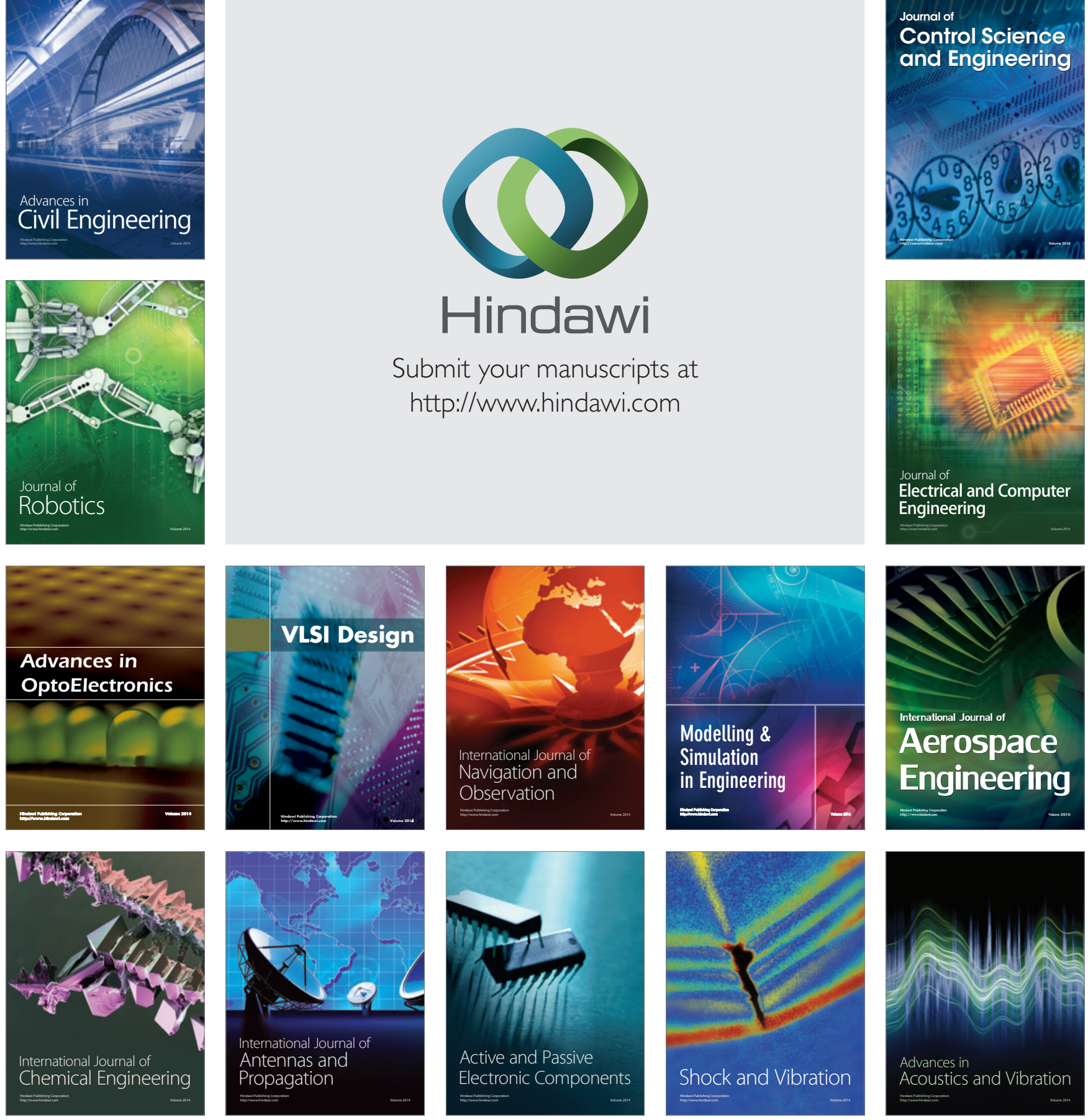